\title{
TOWARD MECHANISTIC MODELING OF BOILING HEAT TRANSFER
}

\author{
MICHAEL Z. PODOWSKI \\ Rensselaer Polytechnic Institute, USA \\ E-mail : podowm@rpi.edu
}

Received November 20, 2012

Recent progress in the computational fluid dynamics methods of two- and multiphase phase flows has already started opening up new exciting possibilities for using complete multidimensional models to simulate boiling systems. Combining this new theoretical and computational approach with novel experimental methods should dramatically improve both our understanding of the physics of boiling and the predictive capabilities of models at various scale levels. However, for the multidimensional modeling framework to become an effective predictive tool, it must be complemented with accurate mechanistic closure laws of local boiling mechanisms.

Boiling heat transfer has been studied quite extensively before. However, it turns out that the prevailing approach to the analysis of experimental data for both pool boiling and forced-convection boiling has been associated with formulating correlations which normally included several adjustable coefficients rather than based on first principle models of the underlying physical phenomena. One reason for this has been the tendency (driven by practical applications and industrial needs) to formulate single expressions which encompass a broad range of conditions and fluids. This, in turn, makes it difficult to identify various specific factors which can be independently modeled for different situations.

The objective of this paper is to present a mechanistic modeling concept for both pool boiling and forced-convection boiling. The proposed approach is based on theoretical first-principle concepts, and uses a minimal number of coefficients which require calibration against experimental data. The proposed models have been validated against experimental data for water and parametrically tested. Model predictions are shown for a broad range of conditions.

KEYWORDS : Boiling Heat Transfer, Mechanistic Models, Subcooled Boiling

\section{INTRODUCTION}

It has already been demonstrated that computational fluid dynamics methods of two- and multiphase flows can be successfully used to perform multidimensional simulations of boiling channels and systems (Kurul and Podowski,1990), (Kurul and Podowski,1991), (Anglart et al., 1997), Alajbegovic et al., 1997), (Podowski et al., 1997), (Podowski, 2008), (Podowski, M.Z. and Podowski, R.M., 2009). However, the accuracy of such simulations strongly depends on the availability of mechanistic closure laws of local boiling mechanisms, especially inside the boundary layer near the heated wall.

Boiling heat transfer, especially pool boiling, has been studied extensively in the past and several different correlations (Rohsenow, 1952), (Foster and Zuber, 1955), (Jens and Lottes, 1962), (Thom, 1966), (Rohsenow, 1973), (Bergles, 1992), and models (Kurul and Podowski, 1990), (Anglart et al., 1997), (Podowski, M.Z. and Podowski, R.M., 2009) have been proposed. Extensive experimental data of Addoms (1948) for water, taken for a broad range of pressures, were compiled by Rohsenow (1952) using the following nondimensional variables

$$
\begin{gathered}
\Delta T^{*}=\frac{c_{p, l}\left(T_{w}-T_{s a t}\right)}{h_{f g} P r_{l}^{1.7}}=\frac{c_{p, l}}{h_{f g} P r_{l}^{1.7}} \Delta T \\
q^{\prime \prime *}=\frac{q^{\prime \prime}}{\mu_{l} h_{f g}} \sqrt{\frac{\sigma}{g\left(\rho_{l}-\rho_{v}\right)}}
\end{gathered}
$$

The Addoms data compiled by Rohsenow is shown in Figure 1.

Rohsenow also used the Addoms data to formulate the following correlation

$$
\Delta T^{*}=C_{s f}\left(q^{\prime * *}\right)^{1 / 3}
$$

The predictions using Eq.(3) are shown in Figure 1 as a thick solid line.

This correlation was later extended by Mikic and Rohsenow (1969) to other fluids and different surfaces, still assuming a pressure-independent value of the coefficient, $C_{s f}$, in Eq.(3). In this case, the goal was to improve the 


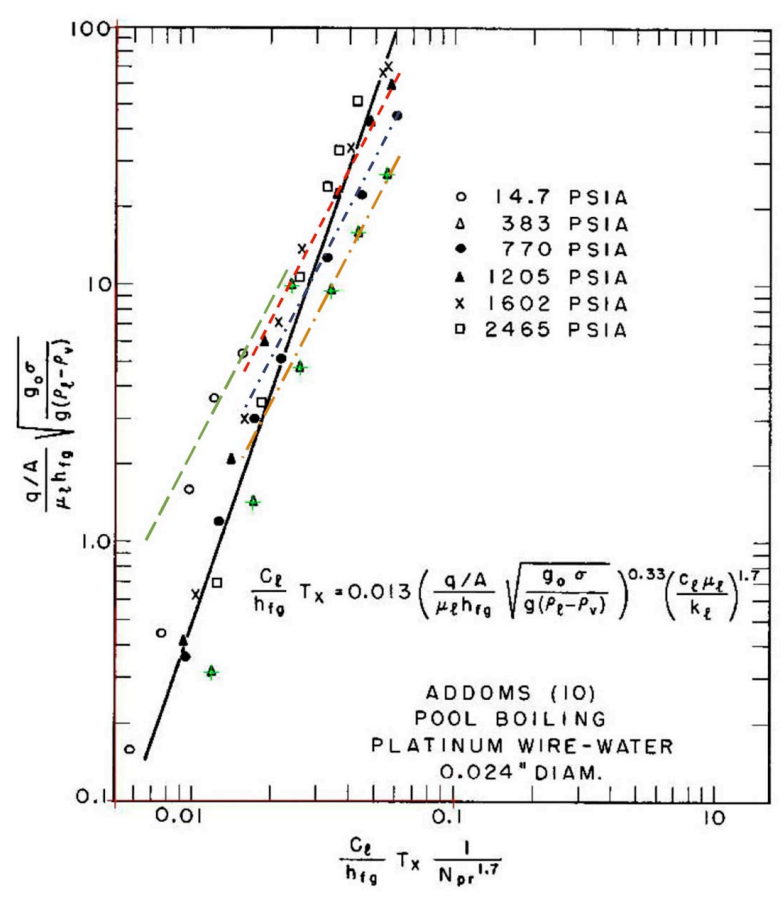

Fig. 1. Comparisons between the Experimental Data of Addoms Complied by Rohsenow (1952) for Pool Boiling in Water and the Model Given by Eq.(11). The Solid Line

Corresponds to the Expression Proposed by Rohsenow (Eq.(1) with $\left.C_{s f}=0.013\right)$. The Dashed Lines Refer to a Different Constant Pressure Each, as Follows:

-- - - 1 atm (14.7 psia), - - - - - 26 atm (383 psia),

....... $52 \mathrm{~atm}$ (770 psia), -..... $82 \mathrm{~atm}$ (1205 psia). accuracy of predictions by introducing several adjustable constants and varying the power coefficient to which the Prandtl number is raised in Eq.(1). However, the complexity of the proposed formula makes it practically impossible to identify and model the physical phenomena which affect, and govern, the efficiency of boiling heat transfer for specific situations.

Mechanistic modeling concepts have also been applied to capture local instantaneous aspects of wall heat transfer during the ebullition cycle (Podowski et al., 1997), (Podowski, M.Z. and Podowski, R.M., 2009). In this approach, the time-dependent aspects of the non-boiling and boiling modes of heat transfer inside the boundary layer at the wall have been combined with conduction heat transfer inside the heated wall. The results of a study by Situ et al. (2007), shown in Figure 2, illustrate how this mechanistic model compared against a wide range of experimental data. Interestingly, practically all other comparisons shown in Figure 1 refer to correlations rather than to physicallybased models.

Because of its practical importance, forced-convection nucleate boiling has also been studied very extensively, resulting in the development of several correlations for wall temperature superheat in both subcooled and bulk boiling. In some of them, attempts have been made to separately account for the effects of single-phase convection and the evaporation heat transfer (Bergles, 1992). Some others reflect the combined effects in a single expression for the wall superheat as a function of heat flux
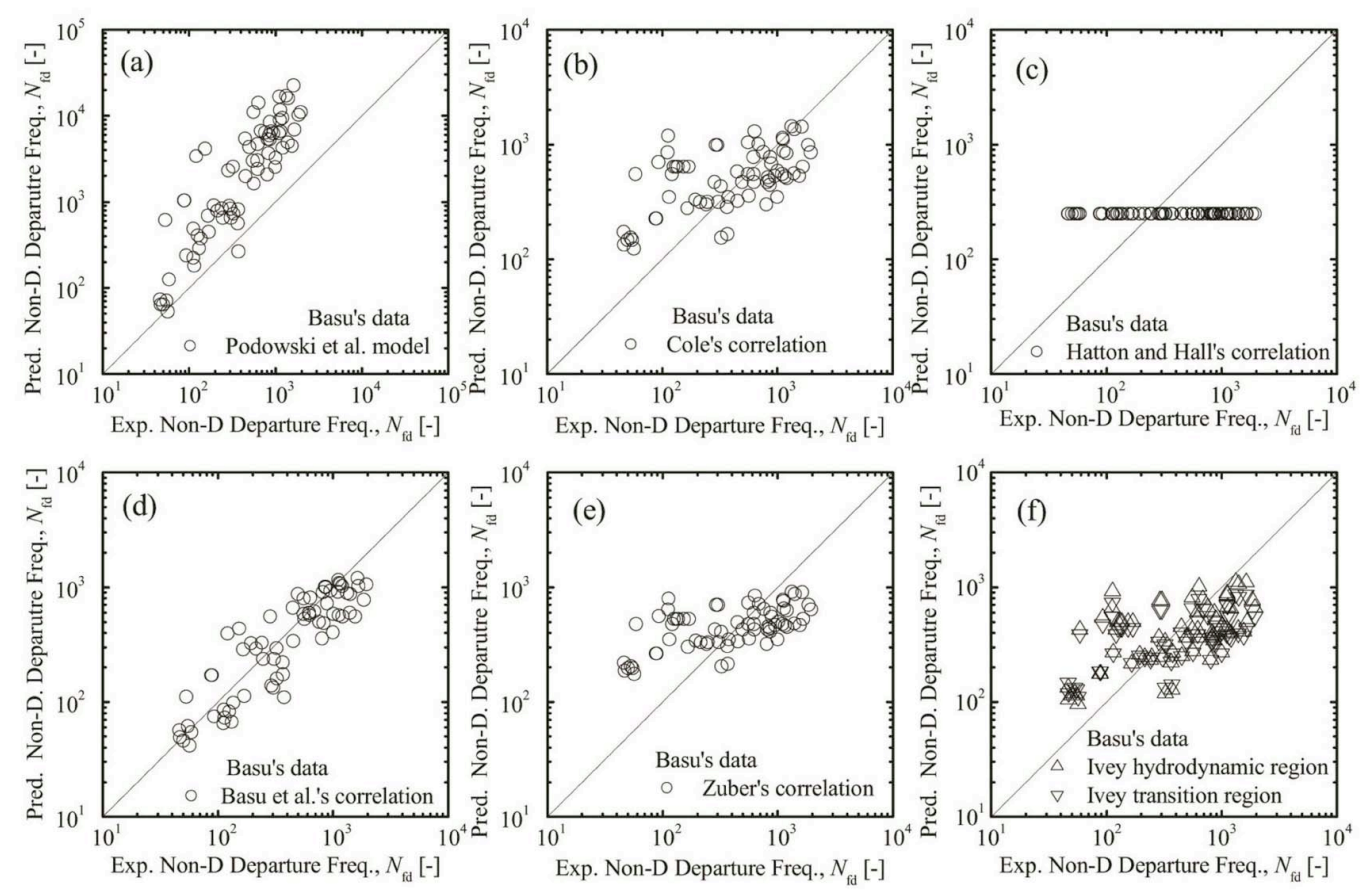

Fig. 2. A Comparison of the Accuracy of Bubble Nucleation Predictions by the Model of Podowski et al. (1997) and Various Correlations for the Experimental Data of Basu (Reproduced from Situ et al. (2007)). 
and operating conditions. Typical formulae are the JensLottes (1962) and Thom (1966) correlations. They are respectively given by:

$$
\begin{aligned}
& \frac{q^{\prime \prime}}{10^{6}}=\frac{\operatorname{Exp}(4 p / 6.2)}{25^{4}} \Delta T^{4} \\
& \frac{q^{\prime \prime}}{10^{6}}=\frac{\operatorname{Exp}(2 p / 8.7)}{22.7^{2}} \Delta T^{2}
\end{aligned}
$$

where $p$ is in [MPa], $q$ " is in $\left[\mathrm{W} / \mathrm{m}^{2}\right]$ and $\Delta T$ is in [K].

It turns out that both correlations agree reasonably well against data for low heat fluxes (although they normally slightly overpredict the wall superheat), whereas only the Jens-Lottes correlation is applicable to boiling heat transfer at high heat fluxes.

Both above mentioned correlations are considered to be applicable to both saturated (bulk) and subcooled boiling. This, in turn, confirms an important general experimental observation that for high heat fluxes the wall temperature in the subcooled boiling region is practically independent of the local liquid subcooling.

Detailed modeling of local phenomena of subcooled boiling in heated tubes or channels normally involves combining a multidimensional model of two-phase flow and heat transfer inside the channel with a model of coupled single-phase and boiling heat transfer phenomena in the near-wall region.

To model the local near-wall heat transfer (Kurul and Podowski, 1990) proposed an approach based on partiti- oning the total wall heat flux into three terms

$$
q^{\prime \prime}=q_{1 \phi}^{\prime \prime}+q_{e}^{\prime \prime}+q_{Q}^{\prime \prime}
$$

where $q_{1 \phi}^{\prime \prime}$ is the single-phase heat transfer component corresponding to the non-boiling sections of the heated wall, $q_{1 \phi}^{\prime \prime}$ is the quenching component associated with heating the liquid which approaches the wall after bubble departure, and $q_{1 \phi}^{\prime \prime}$ is the rate of heat transfer which is directly used to convert liquid into vapor at the heated wall.

\section{MECHANISTIC MODEL OF POOL BOILING HEAT TRANSFER}

The objective of this Section is to present a new mechanistic modeling concept for pool boiling. The method of analysis is based on upgraded and revised theoretical firstprinciple concepts originally introduced in (Podowski, 2009), and its focus is on the effect of heat flux on wall superheat for a wide range of pressures. The proposed approach uses a minimal number of coefficients which require calibration against experimental data.

The nucleation process at the heated surface with cavities of various sizes can be illustrated using Fig. 3.

The well-established theoretical condition for bubble nucleation from a cavity of any size is based on the observation that the vapor produced inside the cavity forms a hemispherical bubble outside the cavity. This, in turn means that the temperature of vapor inside the bubble (and of the liquid at the other side of the vapor/liquid interface at the top of the hemispherical microbubble) becomes equal

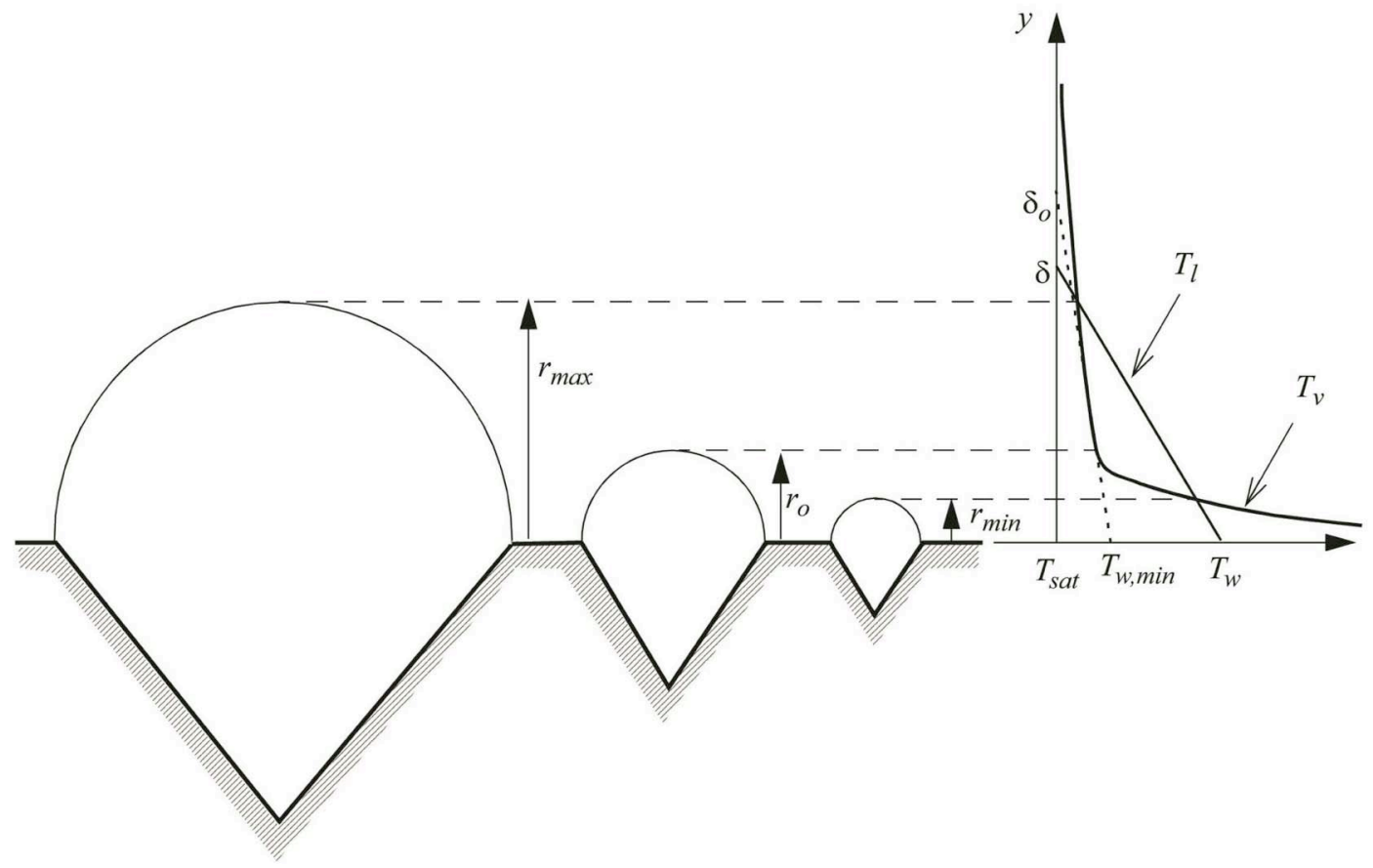

Fig. 3. An Illustration of Bubble Nucleation Process. 
to the liquid temperature inside the laminar boundary layer at the distance from the wall equal to the radius of the corresponding cavity. Starting with the Clausius-Clapeyron equation, the following expression can be derived for the minimum wall superheat at the onset of nucleation

$$
\Delta T_{\text {min }}=T_{w, \min }-T_{s a t}=2 \sqrt{2 \sigma \frac{q^{\prime \prime}}{k_{l}} \frac{\mathrm{v}_{f g} T_{s a t}}{h_{f g}}}
$$

The corresponding critical cavity size (see Fig. 3) can be evaluated from

$$
r_{o}=\sqrt{2 \frac{k_{l}}{q^{\prime \prime}} \frac{\sigma \mathrm{v}_{f g} T_{s a t}}{h_{f g}}}
$$

For well-established pool boiling, the actual wall superheat is significantly higher than the value obtained from Eq.(7). For a surface which contains a large spectrum of cavity sizes, the number of active cavities increases with the wall heat flux. This is illustrated in Fig. 2, where the range of active cavities for a given wall temperature, $T_{w}$, is, $r_{\min } \leq r_{c} \leq r_{\max }$.

For given: heat flux and critical cavity size, the actual range of active cavities can be determined in terms of the ratios: $r_{\max } / r_{o}$ and $r_{o} / r_{\min }$ as

$$
\frac{r_{\max }}{r_{o}}=\frac{r_{o}}{r_{\min }}=\frac{\Delta T}{\Delta T_{\min }}+\sqrt{\left(\frac{\Delta T}{\Delta T_{\min }}\right)^{2}-1}=\Psi+\sqrt{\Psi^{2}-1}
$$

where

$$
\Psi=\frac{T_{w}-T_{\text {sat }}}{T_{w, \min }-T_{\text {sat }}}=\frac{\Delta T}{\Delta T_{\min }}
$$

Using Eq.(7), Eq.(10) can be rewritten as

$$
\Delta T_{w, m}^{*}=C_{p b, m}\left(q^{\prime^{*}}\right)^{0.5}
$$

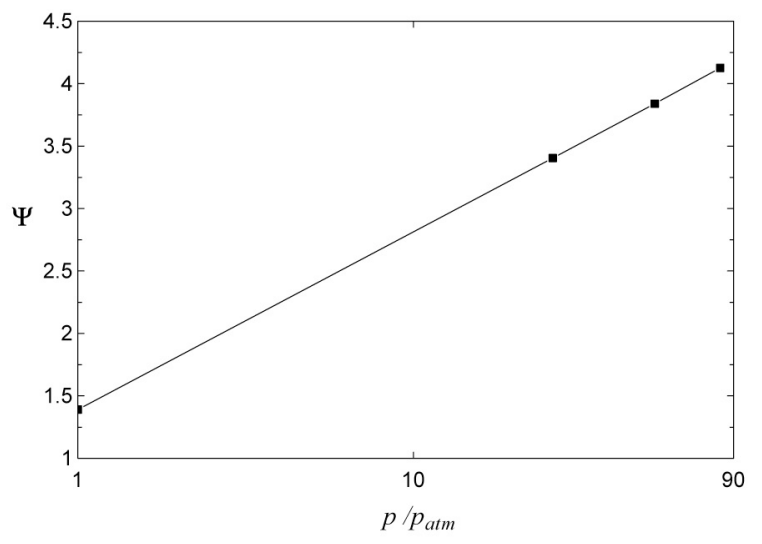

(a) where

$$
C_{p b, m}=2 \Psi \frac{c_{p}}{h_{f g} P r^{m}} \sqrt{\frac{2 \mu_{l} v_{f g} T_{s a t}}{k_{l}} \sqrt{\sigma g\left(\rho_{l}-\rho_{v}\right)}}
$$

is the pool-boiling coefficient of proportionality between $\Delta T_{w, m}^{*}$ and $\left(q^{\prime *}\right)^{0.5}$.

As it can be seen, the analysis performed so far has been based purely on theoretical considerations, without using any adjustable coefficients. Also, the only parameters in Eqs.(11) and (12) which have yet to be determined are: $C_{p b, m}$ (for any given $m$ ) and/or $\Psi$. This, in turn, can be done by examining the experimental data shown in Fig. 3 for one pressure at a time.

A very important conclusion is obtained by rewriting Eq.(12) as

$$
C_{p b, m} \operatorname{Pr}^{m}=2 \Psi \frac{c_{p}}{h_{f g}} \sqrt{\frac{2 \mu_{l} v_{f g} T_{s a t}}{k_{l}} \sqrt{\sigma g\left(\rho_{l}-\rho_{v}\right)}}=F(p)
$$

Specifically, it can be readily noticed that the product, $C_{p b, m} \mathrm{Pr}^{m}$, is independent of $m$ and assumes a constant value for any given pressure. Furthermore, the coefficient, $\Psi$, defined by Eq.(10), is also a unique function of the system pressure. A plot of $\Psi$ as a function of the relative pressure, $p / p_{a t m}$, is presented in Figure 4(a). The corresponding analytic approximation is given by

$$
\Psi=1.39+0.62 \ln \left(\frac{p}{p_{\text {atm }}}\right)
$$

As indicated above, the value of the coefficient, $C_{p b, m}$, depends on the choice of $m$. Whereas $m$ can be selected arbitrarily (including $m=1.7$, which was originally proposed by Rohsenow), is useful for practical reasons to use a value which yields a convenient expression for $C_{p b, m}$

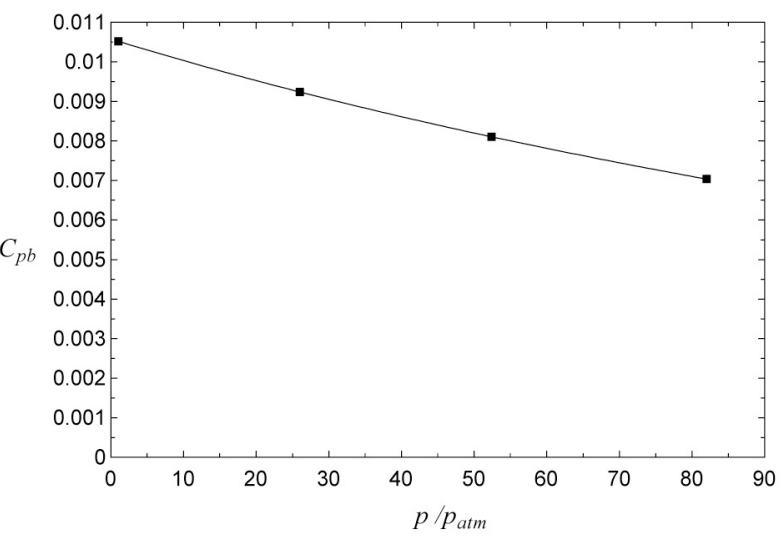

(b)

Fig. 4. The Discrete Data Points (Squares) Give the Values of: (a) $\Psi$, and (b) $C_{p b, m}$ for $=0.95$, which Correspond to the Experimental Data for Each of the four Pressures Indicated in Figure 1. The Solid Lines are the Plots of the Functions Given by: (a) Eq.(14), and (b) Eq.(15). 
as a function of pressure. One such choice is, $m=0.95$. In such a case, the resultant coefficient, $C_{p b}$

$$
C_{p b}=2 \Psi \frac{c_{p}}{h_{f g} P r^{0.95}} \sqrt{\frac{2 \mu_{l} v_{f g} T_{s a t}}{k_{l}} \sqrt{\sigma g\left(\rho_{l}-\rho_{v}\right)}}
$$

can be approximated by

$$
\begin{aligned}
C_{p b}=0.01[1.058 & -0.0056 \frac{p}{p_{a t m}} \\
+ & \left.\left(0.0045 \frac{p}{p_{a t m}}\right)^{2}-\left(0.0037 \frac{p}{p_{a t m}}\right)^{3}\right]
\end{aligned}
$$

In general, the present analysis shows that pool boiling in water over a broad range of pressures can be predicted using a consistent theoretical model which requires only a single factor determined based on experimental data and given by Eq.(13).

It should also be mentioned that the proposed model is valid for the values of heat fluxes for which the effect of single-phase natural convection becomes negligible. A typical minimum value applicable to all pressures is, $q^{\prime \prime} \approx$ $10^{6}\left[\mathrm{~W} / \mathrm{m}^{2}\right]$, but for the near-atmospheric pressures its applicability extends to heat fluxes as low as, $q^{\prime \prime} \approx 5 \cdot 10^{5}$ $\left[\mathrm{W} / \mathrm{m}^{2}\right]$, or less.

\section{FORCED-CONVECTION SUBCOOLED BOILING}

The modeling of local phenomena of subcooled boiling in heated tubes or channels combines a system of multidimensional conservation equations of two-phase flow and heat transfer inside the channel with a model of coupled single-phase and boiling heat transfer in the near-wall region. It has already been shown that a multifield model of two and multi-phase flows provides an appropriate analytic tool for this purpose. The multifield modeling concept assumes that each phase is repre-sented by a separate field (or fields). In the case of subcooled boiling at a constant pressure, a two-fluid model of dispersed bubble flow can be used, given be the following set of mass, momentum and energy conservation equations (Podowski, 2009a)

$$
\begin{gathered}
\frac{\partial\left(\alpha_{k} \rho_{k}\right)}{\partial t}+\nabla \cdot\left(\alpha_{k} \rho_{k} \overline{\mathbf{v}}_{k}\right)=\Gamma_{k} \\
\frac{\partial\left(\alpha_{k} \rho_{k} \overline{\mathbf{v}}_{k}\right)}{\partial t}+\nabla \cdot\left(\alpha_{k} \rho_{k} \overline{\mathbf{v}}_{k} \overline{\mathbf{v}}_{k}\right)=-\alpha_{k} \nabla \bar{p}+\alpha_{k} \nabla \cdot \overline{\underline{\tau}}_{k}^{t} \\
+\mathbf{M}_{k}^{i}+\alpha_{k} \rho_{k} \mathbf{g}+\Gamma_{k} \overline{\mathbf{v}}_{k}^{i} \\
\frac{\partial\left(\alpha_{k} \rho_{k} \bar{h}_{k}\right)}{\partial t}+\nabla \cdot\left(\alpha_{k} \rho_{k} \overline{\mathbf{v}}_{k} \bar{h}_{k}\right)=-\alpha_{k} \nabla \cdot \overline{\mathbf{q}}_{k}^{\prime t} \\
-\left(\overline{\mathbf{q}}_{k}^{\prime \prime t}-\overline{\mathbf{q}}_{k}^{\prime i}\right) \cdot \nabla \alpha_{k}+\Gamma_{k} \bar{h}_{k}^{i}
\end{gathered}
$$

where $k=l$ for the liquid field and $k=v$ for the vapor field, $\alpha_{k}, \rho_{k}, \overline{\mathbf{v}}_{k}$ and $\bar{h}_{k}$ are the volume fraction, density, velocity and specific internal energy, respectively, of field $-k, \bar{p}$ the pressure, $\Gamma_{k}=-\Gamma_{l}=\Gamma$ is the evaporation rate per unit volume, $\boldsymbol{\tau}_{k}^{t}$ is the total shear stress, $\mathbf{M}_{k}^{i}$ is the total interfacial force, $\mathbf{q}_{k}^{t}$ is the local total heat flux, and the terms with the superscript ' $i$ ' represent the interfacial quantities.

It has already been shown (Podowski, 2009), (Podowski, 2012) that a consistent mechanistic model of subcooled boiling is obtained by replacing the original partitioning of the total heat flux proposed by Kurul and Podowski (1990) (see Eq.(6)) by the following expression

$$
q^{\prime \prime}=q_{B}^{\prime \prime}+q_{1 \phi}^{\prime \prime}
$$

where $q_{B}^{\prime \prime}$ is the boiling component, and $q_{1 \phi}^{\prime \prime}$ is the nonboiling (or single-phase heat transfer component).

The single-phase component of the total heat flux in Eq.(20) can still be evaluated as suggested by Kurul and Podowski (1990)

$$
q_{1 \phi}^{\prime \prime}=\rho_{l} c_{p l} u_{l} S t_{l}\left(T_{w}-T_{l}\right)\left(1-A_{B, e f f}^{\prime \prime}\right)
$$

where $A_{B, \text { eff }}^{\prime \prime}$ is the fraction of the heated surface which pertains to boiling, the subscript, ' $l$ ', refers to the liquid phase parameters at a near-wall location, and the remaining notation is conventional. It should be noted that in computational CFD-type models the liquid parameters are evaluate at the closest-to-wall nodal locations where they adhere to the "law of the wall" conditions.

The original portioning of the boiling heat flux into the evaporation and quenching terms (Kurul and Podowski, 1990), (Kurul and Podowski, 1991) required that several phenomenological laws had to be used to achieve model closure. It turns out that the first principle mechanistic aspects of model formulation can be significantly enhanced by evaluating the boiling component from

$$
q_{B}^{\prime \prime}=\rho_{v} h_{f g} V_{b} f n^{\prime \prime}
$$

where $V_{b}=\pi d_{b}^{3} / 6$ is the volume of departing bubbles, $f$ is the nucleation frequency, and $n^{\prime \prime}$ is the nucleation site density.

Several models have been developed to date for the equivalent bubble radius at departure. As can be seen in Figure 5 , the bubble diameter at departure, $d_{b}$, is mainly a function of system pressure and changes only slightly with the wall heat flux (at atmospheric pressure, a typical range is between $1 \mathrm{~mm}$ and $12 . \mathrm{mm}$ ).

Similarly, the frequency of nucleation can be evaluated from one of the existing models, such as the Zuber (1962) model. The nucleation site density can evaluated using a modification of the approach proposed by Podowski (2009) to account for the effect of minimum wall temperature at which the nucleation starts

$$
n^{\prime \prime}=\kappa\left(T_{w}-T_{w}^{\min }\right)^{2}
$$

where $T_{w}^{\min }=T_{\text {sat }}+\Delta T_{w}^{\min }$ and $\Delta T_{w}^{\min }$ is the minimum wall superheat at the onset of nucleation. 


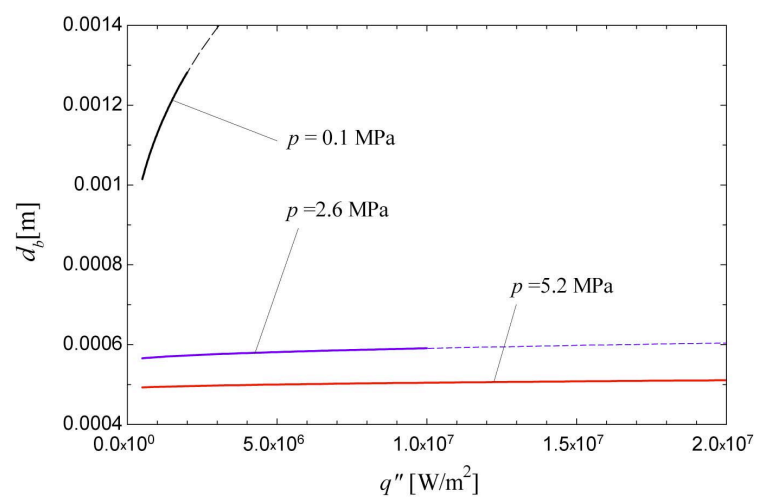

Fig. 5. Effect of Pressure on Bubble Diameter at Departure (Jensen and Memmel, 1986).

The term, $A_{B, \text { eff }}^{\prime \prime}$ in Eq.(21) is the area fraction of the heated surface which pertains to boiling

$$
A_{B, e f f}^{\prime \prime}=n^{\prime \prime} A_{e f f}^{\text {bubble }}
$$

where $A_{e f f}^{\text {buble }}$ is the effective boiling area per single bubble.

The zone of bubble influence can be expressed as

$$
A_{e f f}^{b u b b l e}=\varepsilon A_{c s}^{\text {bubble }}
$$

where $A_{c s}^{b u b b l e}=\frac{\pi d_{b}^{2}}{4}$ is the actual bubble cross-section area. The coefficient, $\varepsilon$, in Eq.(25) can be determined using the conservation of energy principle given by Eq.(22) at the locations where the entire heated wall is subject to boiling heat transfer and where the boiling area fraction reaches a maximum value of one. Specifically, we write

$$
n_{\max }^{\prime \prime}=\frac{q^{\prime \prime}}{\rho_{v} h_{f g} V_{b} f}
$$

where $n_{\max }^{\prime \prime}$ is the maximum nucleation site density corresponding to $A_{B, \text { eff }}^{\prime \prime}=1$.

Substituting Eq.(25) and Eq.(26) into Eq.(24), yields

$$
\varepsilon=\frac{\rho_{v} h_{f g} f}{q^{\prime \prime}} \frac{V_{b}}{A_{c s}^{b u b l e}}=\frac{2 \rho_{v} h_{f g} d_{b} f}{3 q^{\prime \prime}}
$$

Combining Eq.(20) and Eq.(21), we write

$$
q_{B}^{\prime \prime}+\rho_{l} c_{p l} u_{l} S t_{l}\left(T_{w}-T_{l}\right)\left(1-A_{B, e f f}^{\prime \prime}\right)=q^{\prime \prime}
$$

Now, assuming that the bubble diameter and nucleation frequency are modeled separately, and that $T_{l}$ and $u_{l}$ are known, the combined equations, Eqs.(22)-(25) and Eq.(28), with $\varepsilon$ given by Eq.(27), yield a system of four equations with four unknowns: $q_{B}^{\prime \prime}, T_{w}, n^{\prime \prime}$ and $A_{B, \text { eff }}$.

It is important to notice that in the subcooled boing region where the entire heated wall is subject to boiling, i.e., where $A_{B, \text { eff }}^{\prime \prime}=1$, the liquid temperature inside the laminar microlayer at the wall stays close to the saturation temperature even though $T_{l}<T_{\text {sat }}$. Based on the recent theoretical studies of the ebullition cycle (Podowski, 2009; Podowski, 2012) it can also be shown that for this region a rigorous analytic relationship can be derived between the: boiling heating rate per single nucleation site, frequency of nucleation, and heated wall temperature

$$
F\left(q_{n}, f, T_{w}\right)=0
$$

where

$$
q_{n}=\frac{q^{\prime \prime}}{n_{\max }^{\prime \prime}}=\rho_{v} h_{f g} V_{b} f
$$

is the boiling heat transfer rate per single nucleation site.

Combining Eq.(30) with Eq.(23), for given $V_{b}$ and $f$, allows one to evaluate the wall temperature (or superheat) as a function of wall heat flux. Note that in the region where $A_{B, \text { eff }}^{\prime \prime}=1$ (including both subcooled and bulk boiling sub-regions), the wall temperature stays approximately constant along the flow. Naturally, this is true as long as nucleate boiling regime is maintained inside the heated channel.

To confirm the predictive capabilities of the model discussed above, it has been used to evaluate the wall temperature for two experimental data sets, each corresponding to different: geometry, pressure, flow rate and wall heat flux. In both cases, the position dependent nearwall liquid velocity and temperature were taken as numerically calculated by Kurul and Podowski (1991) at the nextto-wall nodal points $\left(u_{l}=u_{P}\right.$ and $\left.T_{l}=T_{P}\right)$ using the model given by Eqs.(17)-(19), combined with a $k$ - $\varepsilon$ model of turbulence.

The results are shown in Figures 6 and 7. Both figures also include the predictions obtained by the earlier model of Kurul \& Podowski (1991) (also, see (Podowski, 1992)). It can be readily noticed that the present approach has led to a significant improvement of the accuracy of predictions. Interestingly, the wall temperature distributions calculated using the current model are similar to those obtained before using an earlier version of the model of subcooled boiling heat transfer. It is important to notice that according to both model predictions and experimental data, the heated wall is subject to complete boiling starting at approximately $2.3 \mathrm{~m}$ from the inlet in Figure 6, and at $0.5 \mathrm{~m}$ from the inlet in Figure 7.

\section{SUMMARY AND CONCLUSIONS}

Selects aspects of boiling heat transfer have been discussed and new mechanistic modeling concepts for both pool boiling and forced-convection boiling have been presented.

The new model of pool boiling has been validated against several sets of experimental data for water, showing very good agreement. The wall heat transfer model in forced-convection subcooled boiling has been compared against two independent high-pressure data sets, each corresponding to different operating conditions. Again, the predicted wall temperature agreed well with the measured values. Still, the current results should be viewed as an 


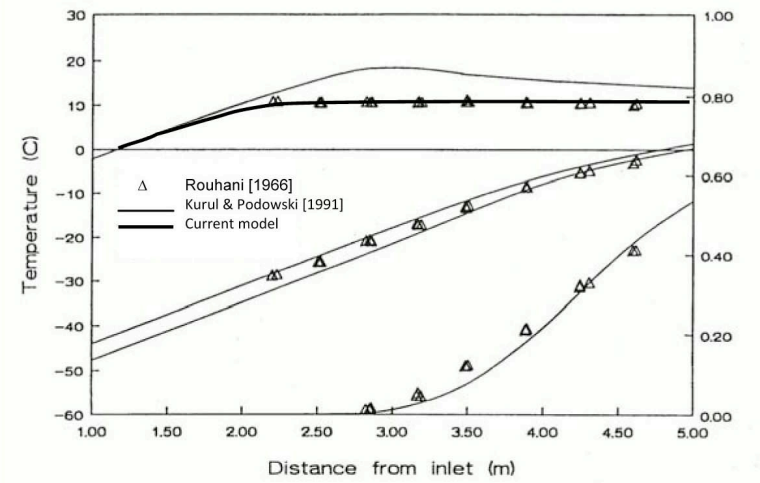

Fig. 6. A Comparison between the Heated wall Temperature along Subcooled Boiling Section of a Uniformly Heated Pipe at a Pressure of $3 \mathrm{MPa}$, Predicted by the Current Model and the Experimental Results of Rouhani (1966).

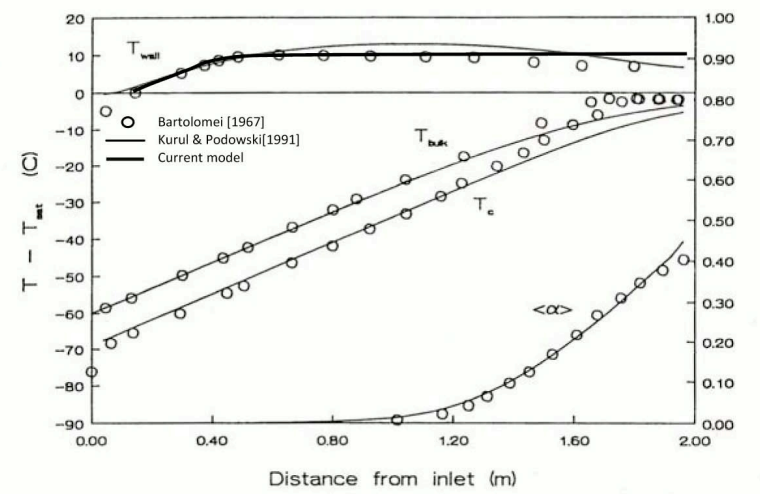

Fig. 7. A Comparison between the Heated wall Temperature along a Subcooled Boiling Section of a Uniformly Heated Pipe at a Pressure of 4.5 MPa, Predicted by the Current Model and the Experimental Results of Bartolomei and Chanturia (1967).

attempt to emphasize first-principle theoretical concepts rather than a comprehensive set of boiling models for a broad range of practical applications. Needless to say, further studies are still needed to validate the proposed models against a well-defined matrix of experimental data, and to update/expand specific modeling assumptions to capture the effect of bubble size, heated surface properties, nucleation frequency, etc.

\section{REFERENCES}

[ 1 ] Addoms, J. N., 1948, Heat Transfer at High Rates to Water Boiling Outside Cylinders, ScD Thesis, Chemical Engineering Department, M.I.T.

[2] Alajbegovic, A., Kurul, N., Podowski, M.Z., Drew, D. and Lahey, R.T., Jr., 1997, “A New Mechanistic Model of Critical Heat Flux in Forced-Convection Subcooled Boiling", Proc. of the Eight International Topical Meeting on Nuclear Reactor Thermal-Hydraulics (NURETH-8), Kyoto, Japan.
[3 ] Anglart, H., Nylund, O., Kurul. N. and Podowski, M.Z., 1997, CFD Simulation of Flow and Phase Distribution in Fuel Assemblies with Spacers, Nuclear Engineering and Design, 177, pp.215-228.

[4 ] Bartolomei, G.G. and Chanturia, V.M., 1967, "Experimental Study of True Void Fraction when Boiling Subcooled Water in Vertical Tubes", Thermal Engineering, Vol. 14, pp.123128.

[ 5 ] Bergles, A.E., 1992, "Elements of Boiling Heat Transfer", in Boiling Heat Transfer; Modern Developments and Advances (R.T., Lahey - editor), Elsevier.

[6 ] Forster, H. K. and Zuber, N., 1955, Dynamics of Vapor Bubbles and Boiling Heat Transfer, AIChE Journal, Vol. 1, p. 531.

[7] Jens, W.H. and Lottes, P.A., 1962, "Analysis of Heat Transfer, Burnout, Pressure Drop and Density Data for High Pressure Water", ANL-4627.

[ 8 ] Jensen, M.K. and Memmel, J.G.J., 1986, Evaluation of Bubble Departure Diameter Correlations, Proc. Eighth Int. Heat Transfer Conf., 4, pp.1907-1912.

[9] Kurul, N. and Podowski, M.Z., 1990, Multidimensional Effects in Forced Convection Subcooled Boiling, Proc. of the 9th International Heat Transfer Conference, Jerusalem, Is-rael.

[10] Kurul, N. and Podowski, M.Z., 1991, On the Modeling of Multidimensional Effects in Boiling Channels, Proc. of the 27th National Heat Transfer Conference, Minneapolis, MN.

[11] Mikic, B.B. and Rohsenow, W.M., 1969, A New Correlation of Pool-Boiling Data Including the Effect of Heating Surface Characteristics, J. Heat Transfer, 91.

[12] Podowski, M.Z., 1992, Two-Phase Flow Dynamics, in Boiling Heat Transfer; Modern Developments and Advances (R.T. Lahey, Jr. - Editor), Elsevier Publishing Corp.

[13] Podowski M.Z., 2008, Multidimensional Modeling of TwoPhase Flow and Heat Transfer, Int. Journal of Numerical Methods for Heat \& Fluid Flow, V. 18, Issue 3/4.

[14] Podowski, M.Z., 2009, On the Consistency of Mechanistic Multidimensional Modeling of Gas/Liquid Two-Phase Flows, Nuclear Engineering and Design, Vol. 239, 5, pp.933-940.

[15] Podowski, M.Z., 2009, Recent Developments in the Modeling of Boiling Heat Transfer Mechanisms, Proc 13th Int. Topical Meeting on Nuclear Reactor Thermal-Hydraulics (NURETH-13), Kanazawa, Japan.

[16] Podowski, M.Z., 2009a, On the Consistency of Mechanistic Multidimensional Modeling of Gas/Liquid Two-Phase Flows, Nuclear Engineering and Design, Vol. 239, 5, pp.933-940.

[17] Podowski, M.Z., 2012, Mechanistic Modeling of Boiling Heat Transfer, Embedded Topical Meeting: Advances in Thermal-Hydraulics, 2012 ANS Winter Meeting, San Diego, CA.

[18] Podowski, R.M, Lahey, R.T., Jr., Drew, D.A. and Podowski, M.Z., 1997, Mechanistic Multidimensional Modeling of Forced-Convection Boiling Heat Transfer, Proc. Eighth Int. Topical Meeting on Nuclear Reactor Thermal-Hydraulics (NURETH-8), Kyoto, Japan, V.3.

[19] Podowski, M.Z. and Podowski, R.M, 2009, Mechanistic Multidimensional Modeling of Forced-Convection Boiling Heat Transfer, Science and Technology of Nuclear Installations, Article ID 387020. 
[20] Rohsenow, W. M., 1952, A Method of Correlating Heat Transfer Data for Surface Boiling of Liquids, Trans. ASME, Vol. 74.

[21] Rohsenow, W.M., 1973, Handbook of Heat Transfer, McGraw-Hill.

[22] Rouhani, Z., 1966, Void Measurements in the Regions of Subcooled and Low-Quality Boiling. Ae-239.

[23] Situ, R., Tu, J. Yeoh, G-H., Hibiki, T., Ishii, M., and Mori, M., J., 2007, Dimensionless Analysis of Bubble Departure
Frequency in Forced Convective Subcooled Boling Flow, Proc. 15th Int. Conf. on Nucl. Eng. ICONE-15-10148, Nagoya, Japan.

[24] Thom, J.R.S. et al., 1966, Boiling in Subcooled Water during Flow in Tubes and Annuli, Proc. Inst. Mech. Eng., 180.

[25] Zuber, N., 1963, Nucleate Boiling - the Region of Isolated Bubbles, Similarity with Natural Convection", Int. J. Heat Mass Transfer, 6, pp. 53-65. 